\title{
Simulation of Microstructure Evolution of AZ31 Magnesium Alloy during Isothermal heating process Based on Cellular Automata
}

\author{
Zhongtang Wang 1, a, Lingyi Wang ${ }^{2, b}$, Shengdong Gao ${ }^{1, c}$ \\ ${ }^{1}$ School of Materials Science and Engineering, Shenyang Ligong University, Shenyang 110159, China \\ ${ }^{2}$ College of information and control technology, Shenyang Institute of Technology, Fushun city, 113122, \\ China \\ aztwang@imr.ac.cn, blywang01@sina.cn, cgaoshengdong2012@163.com
}

Keywords: Magnesium alloy, AZ31, isothermal heating, cellular Automata, dynamic recrystallization.

\begin{abstract}
Microstructure evolution of dynamic recrystallization of AZ31 magnesium alloy during isothermal heating process was simulated by cellular automaton method (CA method). When heat holding time is constant, the grain size of AZ31 magnesium alloy increases significantly with the increase of heating temperature. When heating temperature is constant, the grain size increases slightly with increase of holding time. By compared CA simulation results with experimental results, the maximum relative error is $16.5 \%$. It is proved that cellular automaton method may be used to predict the microstructure evolution of AZ31 magnesium alloy during isothermal heating process.
\end{abstract}

\section{Introduction}

The magnesium alloy has lower stacking fault energy, higher diffusion velocity of grain boundary. Because the stacking fault energy which is on the sub grain boundary can be absorbed easily by the grain boundary, dynamic recrystallization is occurred easily. The nucleation and grain growth of dynamic recrystallization have a decisive influence on the dislocation density. The nucleation of dynamic recrystallization leads to the dislocation accumulation and increase of dislocation density. The growth of grains leads to the dislocation disappearance and reduction of dislocation density.

Cellular automaton (referred to as CA) can be well applied to the simulation analysis of microstructure evolution of dynamic recrystallization process. Rappaz had studied the microstructure evolution of solidification process by CA method [1]. Goetz [2] was the first researcher who had applied CA method to simulate the process of dynamic recrystallization. ZHOU [3] had made deformation process link the CA method to analyze the dynamic recrystallization in the blade forming process. Cellular automaton method can be applied to study in the solidification nucleation, recrystallization and phase transition process [4]. LI [5] had used CA method to study phase transformation process of dynamic recrystallization of TA15 titanium alloy. YANG[6] had improved cellular automaton and transmission model of flow field model, and used it to simulate the microstructure evolution of AZ31 magnesium alloy with equiaxed and columnar structure at the condition of convection, and analyzed the growth law of single dendritic, multi dendritic, and columnar dendritic of magnesium alloy. JIN [7] found that dislocation density distribution is highly uneven after dynamic recrystallization, which is a typical feature of dynamic recrystallization. The influence mechanism of thermal processing parameters on dynamic recrystallization nucleation and growth behavior is by changing the density of dislocation accumulation rate. Huang [8] had used cellular automaton method to research the solidification process of nucleation and growth of magnesium alloy during thin strip casting-rolling, and to analyze the influence law of process parameters on grain size and orientation of magnesium alloy. WU [9] had set up a dendritic growth model of three-dimensional numerical simulation of the cellular automaton of magnesium alloys, and the dendrite growth law of directional solidification process of magnesium alloy had been obtained. WU [10] had used improved cellular automaton method to simulate the microstructure evolution of close-packed hexagonal structure of magnesium alloy, the dendrite growth model which is along different the grain orientation had been established. 
In this paper, cellular automaton method is used to simulate the process of dynamic recrystallization during heating process. The influence of process parameters on microstructure is analyzed. Mathematical model between grain size and heating process parameters had been carried out.

\section{Properties of experiment materials}

Properties of AZ31 magnesium alloy are that initial dislocation density $\left(\rho_{0}\right)$ is $10^{10} \mathrm{~m}^{-2}$, and shear modulus $(\mathrm{G})$ is $17000 \mathrm{MPa}$, and boundary activation energy $\left(\mathrm{Q}_{\mathrm{b}}\right)$ is $134 \mathrm{~kJ} \cdot \mathrm{mol}^{-1}$, and deformation activation energy (Q) is $121 \mathrm{~kJ} \mathrm{~mol}^{-1}$, and constant $\mathrm{K}$ is 6030 , and hardening constant $\left(\mathrm{h}_{0}\right)$ is $10^{13}$, and recovery constant $\left(\mathrm{r}_{0}\right)$ is 17.7 . In experiment study, the heating temperature is $200^{\circ} \mathrm{C}, 250^{\circ} \mathrm{C}, 300^{\circ} \mathrm{C}$, $350^{\circ} \mathrm{C}, 400^{\circ} \mathrm{C}$, respectively, and the holding time is $10 \mathrm{~min}, 20 \mathrm{~min}, 30 \mathrm{~min}, 60 \mathrm{~min}$, respectively.

\section{Effect of heating temperature and holding time on microstructure of AZ31 magnesium alloy}

The microstructure of magnesium alloy sheet during heating process was simulated by CA method. The heating temperature and holding time had an effect on microstructure of magnesium alloy, shown as Fig.1. Corresponding to the microstructure seen as Fig.1, the relation between grain size and heating temperature and holding time is shown as Fig.2. The curves of grain size and heating temperature are shown as Fig.2a. The results show that the grain size of magnesium alloy sheet increases with the increase of heating temperature. When holding time is $10 \mathrm{~min}$ and the heating temperature is $200{ }^{\circ} \mathrm{C}$, $250{ }^{\circ} \mathrm{C}, 300{ }^{\circ} \mathrm{C}, 350{ }^{\circ} \mathrm{C}$, respectably, the grain size is $9.71 \mu \mathrm{m}, 15.12 \mu \mathrm{m}, 25.08 \mu \mathrm{m}, 27.51 \mu \mathrm{m}$, respectably. The grain size increases with the increase of heating temperature, which is due to the static recrystallization in heating process. The curves of grain size and holding time are shown as Fig.2b. When the heating temperature is constant, the grain size increases slightly with the increasing of holding time. The grain size increases significantly with the increase of heating temperature.
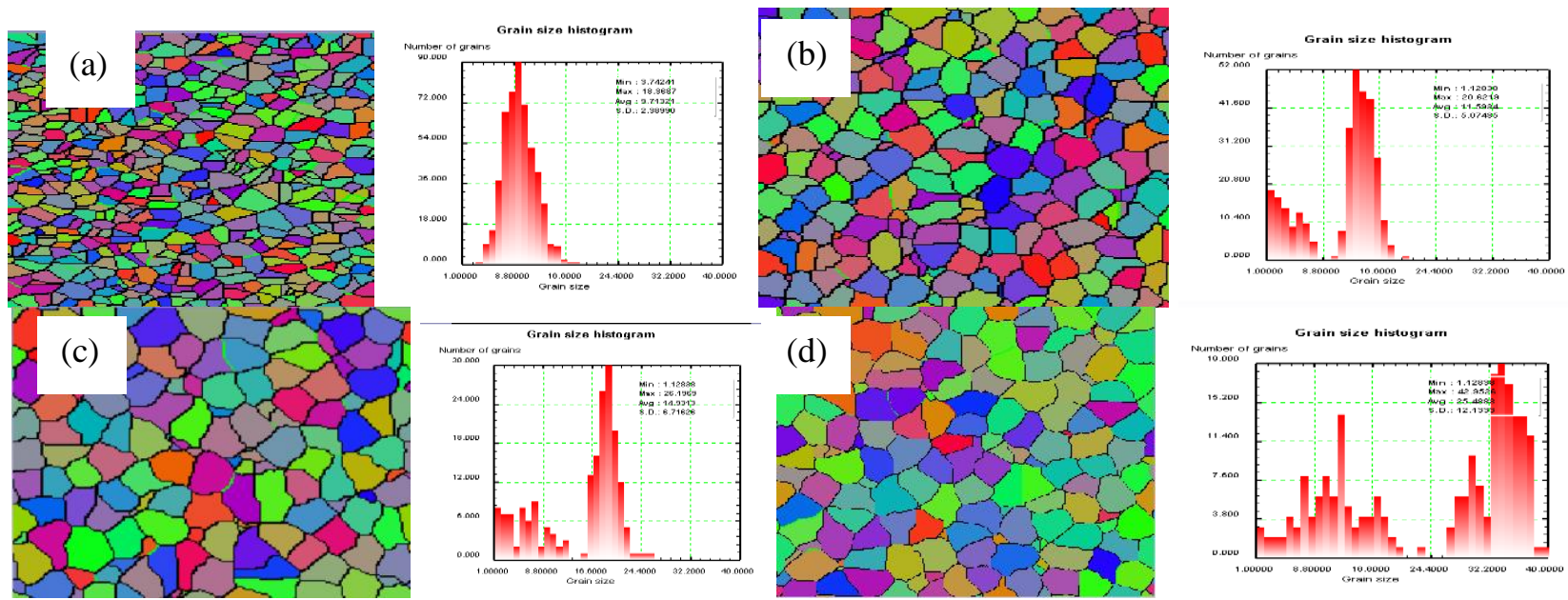

Fig. 1 Microstructure and grain size distribution of AZ31 magnesium alloy at different heating temperature when holding time is $10 \mathrm{~min}$ (a, heating temperature $200{ }^{\circ} \mathrm{C}$; b , heating temperature $250^{\circ} \mathrm{C}$; c, heating temperature $300^{\circ} \mathrm{C}$; d, heating temperature $350^{\circ} \mathrm{C}$ ) 

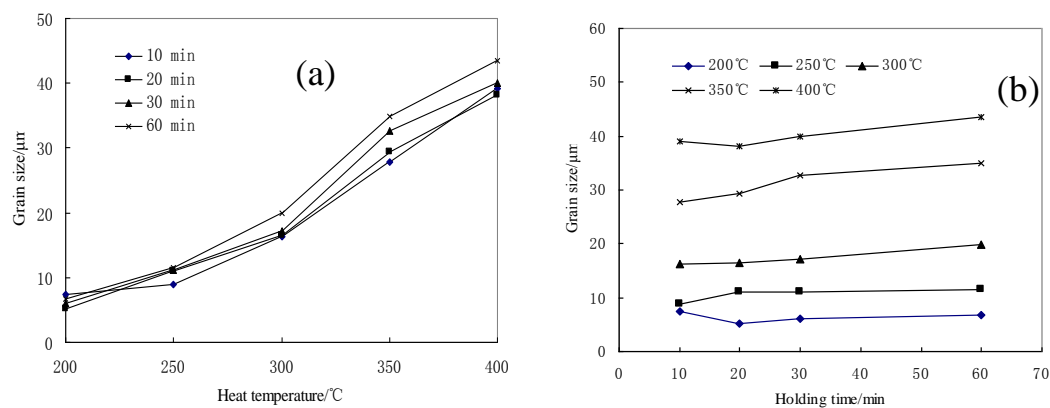

Fig. 2 Grain size of AZ31 magnesium alloy sheet during heating process (a, grain size with heating temperature; $b$, grain size with holding time. )

\section{Analysis of simulation results and experimental results}

The comparison between the simulation results and the experimental results of the AZ31 magnesium alloy sheet during heating process by CA method is shown as Fig.3. Comparison of simulation results and experimental results is shown as Fig.4. The relative errors between simulation results and experiment results are less than $16.5 \%$

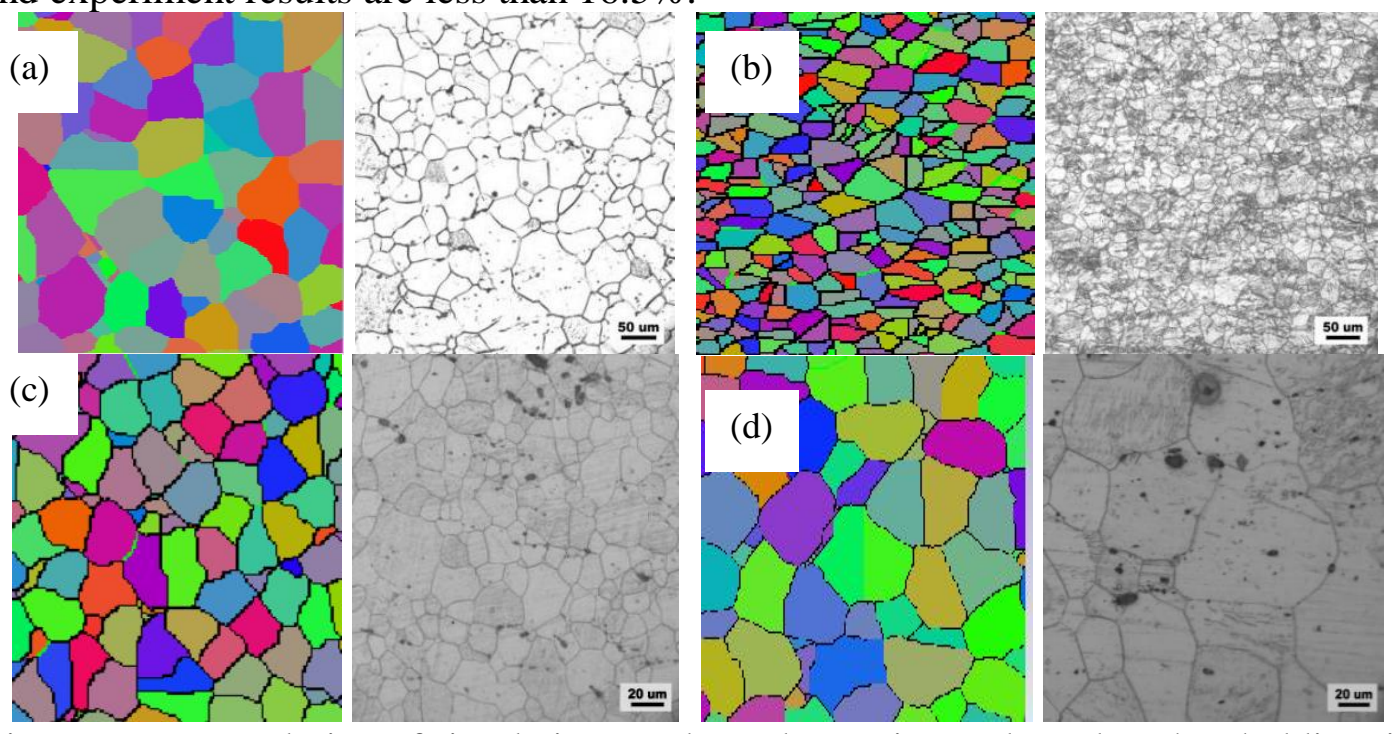

Fig. 3 Microstructure evolution of simulation results and experimental results when holding time is 10 $\min \left(\mathrm{a}\right.$, original; $\mathrm{b}$, heating temperature $200{ }^{\circ} \mathrm{C}$; $\mathrm{c}$, heating temperature $300{ }^{\circ} \mathrm{C}$; $\mathrm{d}$, heating temperature $\left.400^{\circ} \mathrm{C}\right)$
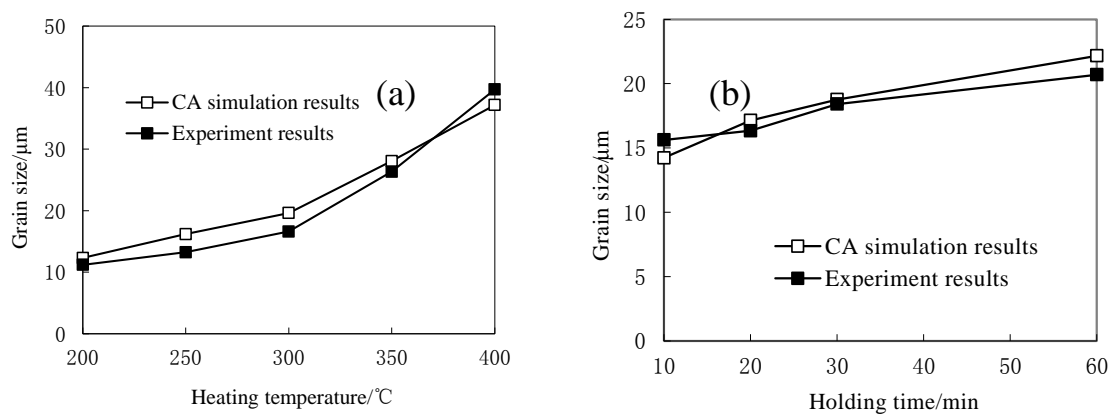

Fig. 4 Comparison of simulation results and experimental results (a, holding time $10 \mathrm{~min}$; $\mathrm{b}$, heating temperature $300^{\circ} \mathrm{C}$ ) 


\section{Conclusion}

(1)Microstructure evolution of dynamic recrystallization of AZ31 magnesium alloy during isothermal heating process was simulated by cellular automaton method (CA). By compared the simulation results with the experimental results, the maximum relative error is $16.5 \%$.

(2) When holding time is constant, the grain size of AZ31 magnesium alloy increases significantly with the increase of heating temperature. When heating temperature is constant, the grain size increased slightly with increase of holding time.

\section{Acknowledgements}

This project is supported by National Natural Science Foundation of China (Grant No. 51575366).

\section{References}

[1] Rappaz M, Gandin Ch A. Probabilistic modelling of microstructure formation in solidification processes. Acta Metallurgica Materialia. Vol.41 (1993) No.2, p. 345-360.

[2] Goetz R L, Seetharaman V. Modeling dynamic recrystallization using cellular automata. Scripta Materialia. Vol.38 (1998) No.3, p.405-413.

[3] ZHOU Sheng, FU Jian, WANG Tao. Simulation Research on dynamic recrystallization of blade in die-forging based on cellular automata. Hot Working Technology. Vol.38 (2009) No.5, p. 96-100. In Chinese.

[4] Guo Yong-guan, Li Shuang-ming, Liu Lin. CA Simulation of microstructure of directionally solidified DZ125 superalloy. Acta Metallurgica Sinica. Vol.44 (2008) No.3, p.365-370.

[5] Li Ping, Gan Guoqiang, Xue Kemin. Modeling of phase transformation and DRX in TA15 alloy during the isothermal hot compression. Rare Metal Materials and Engineering. Vol.41 (2012) No.S2, p. 343-347. In Chinese.

[6] YANG Man-hong, GUO Zhi-peng, XIONG Shou-mei. Numerical simulation of dendritic growth of magnesium alloy with convection. The Chinese Journal of Nonferrous Metals. Vol.25(2015) No.4, p. 835-843. In Chinese.

[7] JIN Zhaoyang, LI Keyan WU Xintong, YAN Kai. Correlation between dynamic recrytallization and flow characteristic at high temperature of magnesium alloy. Journal of Yangzhou University (Natural Science Edition). Vol.18(2015) No.3, p.41-45. In Chinese.

[8] Huang Feng, Di Hong-Shuang, Wang Guang-Shan. Modelling of solidification microstructure evolution of twin-roll casting magnesium strip using cellular automaton. Acta Physica Sinic., Vol.58 (2009), p.313-318.

[9] Mengwu WU, Shoumei XIONG. A three-dimensional cellular automaton model for simulation of dendritic growth of magnesium alloy. Acta Metallurgica Sinica (Engl. Lett.). Vol.25(2012) No.3, p. 169-178.

[10] WU Meng-wu, XIONG Shou-mei. Modeling of equiaxed and columnar dendritic growth of magnesium alloy. Transactions of Nonferrous Metals Society of China. Vol.22 (2012), p. 2212-2219. 